\title{
O COMPUTADOR NA EDUCAÇÃO EM CIÊNCIAS: BREVE REVISÃO CRÍTICA ACERCA DE ALGUMAS FORMAS DE UTILIZAÇÃO ${ }^{\prime}$ \\ The computer in Science Education: a brief critical review
}

Marcelo Giordan ${ }^{2}$

\begin{abstract}
Resumo: O objetivo deste artigo é discutir algumas das principais questões atuais de pesquisa sobre a presença do computador nas aulas de Ciências. Para apresentar o estado da arte da pesquisa, recuperam-se as primeiras experiências de utilização do computador e também apresentam-se outras experiências de uso da internet, bem como de atividades desenvolvidas diante do computador. Paralelamente às formas de utilização do computador, são discutidas algumas questôes de pesquisa desdobradas das doutrinas de pensamento que alimentam os programas de pesquisa em Educação em Ciências, enfatizando alguns conceitos da teoria da ação mediada.
\end{abstract}

Unitermos: computador, Educação em Ciências, sala de aula, Teoria da Ação Mediada.

Abstract: In this article, we discuss some of the main current research questions on the presence of the computer in Science lessons. The state of the research in this field is reported, through recalling the first experiences on the use of computers and also through presenting other experiences of using the internet, as well as some experiences of activities at the computer. While the uses of computers in science lessons are reported, some research questions from Science Education are also described, with an emphasis on concepts of the mediated action theory.

Keywords: computer, Science Education, classroom, Mediated Action Theory.

\section{Introdução}

O uso de Tecnologias da Comunicação e Informação (TCI) na educação, tem atraído atenção generalizada em diversos países (LANG, 2000; SOMEKH, 2000; PELGRUM, 2001). Grandes projetos de políticas públicas têm sido deflagrados pelo mundo afora, e no Brasil, a situação não é diferente (BRASIL, 1999). Não apenas o poder público tem destinado vultosos recursos para equipar escolas com computadores e acesso à internet, mas também a iniciativa privada mobiliza somas substanciais na informatização das escolas. É inegável, também, que a principal justificativa declarada por ambas as partes é a necessidade de orientar as ações educacionais e, portanto, a formação dos alunos para as necessidades das sociedades que estão imersas, e às vezes imobilizadas, em um mundo globalizado, em que as oportunidades de trabalho exigem cada vez mais conhecimentos e habilidades para agir com computadores. Não há dúvidas sobre as exigências do mercado de trabalho mobilizarem a atenção daqueles que planejam a educação, mas serão elas as definidoras dos propósitos das ações educativas que se realizam em sala de aula?

${ }^{I}$ Versão modificada da conferência plenária, proferida no IV Encontro Nacional de Pesquisa em Educação em Ciências. Bauru, 2003.

${ }^{2}$ Faculdade de Educação, Universidade de São Paulo. Av. da Universidade, 308. Cep: 05508-900, São Paulo, SP, Brasil. E-mail: giordan@fe.usp.br. 
Por certo, não é possível reduzir, nem muito menos orientar toda a dinâmica da sala de aula ao que se supõe ser o núcleo ou a essência dos conhecimentos e das habilidades para agir com o computador, ou agir por meio dele. Isso porque não se trata de eleger princípios norteadores das ações da sala de aula a partir de características singulares das TCI, e menos ainda de se reduzir as açóes humanas a um conjunto universal de atitudes e valores. Estas seriam medidas unilaterais resultantes de uma visão parcial e exterior à sala de aula. Por ignorarem o caráter situado e a multiplicidade de propósitos que perpassam as ações do cotidiano escolar, essas visões são incompletas e agregam baixo valor teórico e metodológico para investigar a dinâmica que ali se instaura a partir da chegada de novos meios mediacionais. Para compreender as funçôes das TCI no ensino e na aprendizagem, é necessário, portanto, focalizar a atenção para os efeitos produzidos pelas suas formas de uso na sala de aula, quando elas estão imersas em um contexto que as toma como meios mediacionais capazes de sustentar a realização de ações motivadas por propósitos definidos pela própria cultura da sala de aula.

Neste artigo, propomos fazer uma reflexão sobre como as pesquisas em Educação em Ciências podem contribuir para a compreensão das potencialidades e limitações dos usos do computador na sala de aula. Para tanto, realizamos uma análise crítica das principais formas de utilização do computador na escola, e em particular, nas aulas de ciências. Esta perspectiva crítica está ancorada em máximas e hipóteses da Teoria da Ação Mediada (WERTSCH, 1991, 1998), sobre a qual já vimos nos apoiando (GIORDAN 2003, 2004, 2005). Assim, na primeira parte, reunimos as principais idéias e decorrências da ação mediada para os usos do computador na sala de aula, para, em seguida, realizar a revisão crítica da literatura das áreas de linguagem de programação, sistemas tutoriais, caixas de ferramentas, simulações e animações, comunicação mediada por computador e interaçóes na sala de aula com a presença do computador.

\section{Teoria da Ação Mediada}

Os estudos socioculturais de raiz marxista, alicerçados nos estudos sobre gênese do conhecimento de Vygotsky e nos estudos literários e lingüísticos de Bakhtin, vêm fundamentando a pesquisa de uma comunidade que produz interfaces com comunidades de pesquisa em educação (WERTSCH, DEL RÍO e ALVAREZ, 1995; SMOLKA, 2000) e em particular na Educação em Ciências (MORTIMER e SMOLKA, 2003). De certa forma, as contribuições de James Wertsch, que produziu algumas das primeiras traduções de psicólogos soviéticos, têm uma influência considerável nessa comunidade. Desde a tradução e edição do "Conceito de atividade na psicologia soviética" (WERTSCH, 1981), Wertsch vem organizando uma parte dos estudos na área de psicologia do desenvolvimento, o que se consolidou com a publicação de "Vygotsky e a formação social da mente" (1985). Nesse livro seminal, Wertsch discute algumas das principais questões teóricas abordadas por Vygotsky e se posiciona em favor de uma dimensão mediada, portanto de matriz semiótica, mas criticando a palavra como unidade de análise básica para analisar da consciência humana. Já inspirado nos estudos de Zinchenko (1985), Wertsch se define pelo estudo da ação mediada por ferramentas como uma unidade de análise mais apropriada para os estudos da consciência.

Em Vozes da mente (WERTSCH, 1991), o autor expõe com mais detalhes sua interpretação sobre os estudos de Bakhtin, um crítico literário interessado em cultura popular e novelas e um arguto estudioso dos discursos sociais. De Bakhtin, Wertsch adotou a noção de dialogia, que combinada à proposição de univocalidade de Lotman a respeito do princípio do dualismo funcional, consolidou-se como um bom dispositivo analítico para estudar a ação mediada. Zinchenko (1995, p. 50) já observara em Wertsch um movimento no sentido de privilegiar a ação como unidade de análise, o que de fato veio a lume com Mente em ação (1998). 
No entanto, a principal influência sobre a idéia de ação mediada em Wertsch (1998) é devida a Keneth Burke, filósofo norte-americano que teria influenciado estudos da antropologia, psicologia, sociologia e crítica social. Wertsch foi buscar em Burke os estudos sobre a "ação humana" e seus "motivos", desenvolvidos para descrever o dramatismo, dos quais se destacam cinco focos de análise. Os cinco elementos do pentagrama de telas terminísticas seriam como "lentes", por meio das quais se organizam metodologias de investigação sobre a ação humana e seus motivos, que seriam conduzidas por perguntas classificadas de acordo com os objetivos da investigação e, portanto, vinculados a uma determinada tradição disciplinar, conforme esquematizado na Figura 1.

\begin{tabular}{|c|c|c|}
\hline Elemento & Pergunta & Natureza da pergunta \\
\hline Ato & O que foi feito? & Ontológica \\
Propósito & Por que foi feito? & Ontológica \\
Agente & Quem fez? & Metodológica \\
Agência & Como ele fez? & Metodológica \\
Cena & Quando e onde foi feito? & Metodológica \\
\hline
\end{tabular}

Figura 1 - Pentagrama das telas terminísticas da ação humana. (Adaptado de BURKE, 1969 p. XV; 1973, p. 68)

Em lugar de focar a análise da ação e dos motivos sob uma das lentes, Burke defende a coordenação de perspectivas de modo a superar o reducionismo disciplinar, o que, longe de ser tarefa simples, poderia repercutir em um relativismo estéril. Wertsch reduz o conjunto de telas terminísticas a dois elementos do pentagrama, especificamente os agentes e suas ferramentas culturais ${ }^{3}$, apresentando entre as justificativas, a superação da perspectiva antropocêntrica de privilegiar o agente individual quando tentamos entender as forças que moldam a ação humana, à qual adicionamos a necessidade de superar a visão determinística da potencialidade das ferramentas culturais sobre a ação humana. Uma segunda justificativa defende que a relação agente-instrumento é suficientemente fértil para sustentar análises sobre os outros elementos do pentagrama. A terceira justificativa valoriza o papel da ferramenta cultural, que por estar inerentemente situada nos contextos cultural, histórico e institucional, quando combinada com o agente, produz uma vigorosa unidade de análise, a ação mediada.

Wertsch sugeriu a existência de algumas propriedades importantes da ação media$\mathrm{da}$, dentre as quais se destaca a interpretação do processo de internalização segundo uma perspectiva de domínio e apropriação. Ele defende a idéia de que o uso de ferramentas culturais particulares conduz ao desenvolvimento de habilidades específicas. Esse argumento não inviabiliza a possibilidade de existirem habilidades genéricas ou inteligência, mas serve para indicar que há um erro na aproximação de se desenvolver habilidades gerais por meio de um conjunto particular de ferramentas culturais (1998, p. 46).

A noção de internalização adotada por Wertsch está diretamente vinculada ao conceito de domínio (mastery), ou "saber como usar habilmente o meio mediacional" (p. 50). Trabalhar com os conceitos de domínio e "saber como" nos permite eliminar algumas noções que o conceito de internalização encerra, como, por exemplo, trazer para o plano interior uma função que se executava no plano exterior. Wertsch admite que algumas funçôes, ou talvez a maioria, não são internalizadas, permanecendo no "exterior que executa seu trabalho, permitindo-nos simplificar o problema em uma série de tarefas padrão reconhecidas, que nós podemos facilmente executar" (p. 51).

${ }^{3}$ Agências, na designação de Burke. 
A idéia de apropriação é inspirada em Bakhtin (1981). Prisvoenie [svoi], do russo, é relativo ao processo de tomar algo do outro e torná-lo seu, próprio. "No sistema de Bakhtin, nós somos todos estranhos [chuzhoi] uns aos outros, por definição: cada um de nós tem sua própria [svoi] linguagem, ponto de vista, sistema conceitual que para os outros é estranho [chuzhoi]. Ser estranho torna o diálogo possível” (HOLQUIST e EMERSON, 1981, apud WERTSCH, 1998, p. 53-4). Bakhtin concebe a linguagem e as locuções em meio à necessária, e sempre presente, tensão entre chuzvoi e svoi; de fato, "linguagem, para a consciência individual, situa-se na fronteira entre o eu e o outro" (1981, p. 293, apud WERTSCH, 1998, p. 54).

Wertsch diferencia claramente domínio de apropriação, duas formas de internalização. É possível que alguém domine, mas não se aproprie de uma ferramenta cultural, como é possível, também, que domínio e apropriação estejam correlacionados em alto ou baixo grau. Os critérios de diferenciação estão definidos pelo comprometimento, resistência e autonomia do agente em executar ações com propósitos específicos.

Um exemplo de ferramenta cultural indicada por Wertsch como bastante significativa para compreender a representação do passado é a narrativa (2002). De fato, se tomarmos as atividades de ensino como eventos situados e deflagrados por narrativas que recuperam ações anteriores e organizam ações dos alunos na sala de aula, é razoável considerar que a estruturação das ações dos agentes usando ferramentas culturais nos cenários da sala de aula, com o propósito de resolver problemas, é condicionada pela narrativa e suas especificidades, como, por exemplo, intertextualidade, contextualização e gêneros discursivos.

Tendo em vista estes conceitos construídos a partir da Teoria da Ação Mediada, passamos a analisar algumas das contribuiçóes que julgamos mais representativas, de seis formas ou situações de utilização do computador na sala de aula de ciências, para, ao final, indicarmos algumas perspectivas para um programa de pesquisa na área.

\section{Linguagens de programação}

As primeiras iniciativas de utilização do computador como recurso de ensino que repercutiram em pesquisas, são devidas a Seymour Papert, que coordenou a criação do Logo. A linguagem de programação Logo foi desenvolvida na década de 1970, no MIT, com o objetivo de criar ambientes nos quais as crianças pudessem aprender a se comunicar com computadores. O Logo passou por diversas adaptaçôes ao longo das suas mais de três décadas de existência e um número significativo de pesquisas foi realizado com o objetivo de compreender como o computador interfere na aprendizagem. Ainda em uma época em que essas máquinas não apresentavam interfaces, hoje em dia consideradas indispensáveis, como o teclado e a tela, Papert apoiou-se nas contribuiçōes de Piaget sobre o desenvolvimento cognitivo da criança, para implementar uma proposta de utilização do computador, na qual os estudantes programavam a máquina para obter figuras geométricas, tendo como motivador um problema a ser resolvido (PAPERT, 1985).

Papert sugeriu que o raciocínio analítico desenvolvido para programar o computador poderia ser transferido para outras situações de resolução de problemas sem a presença da máquina (1985, p. 16). Esta foi uma das hipóteses de pesquisa mais testadas, a qual não se provou consistente, segundo diversos autores, conforme levantamento feito em revisōes sobre o assunto (HUGHES 1990, citado por WEGERIF, 2003; JONASSEN e REEVES, 1996, p. 700). Para eles, a programação em Logo se mostrou particularmente efetiva no desenvolvimento de habilidades cognitivas relacionadas à própria programação em Logo, ou ainda para promover o engajamento dos alunos em aprender, quando a programação fazia parte de uma atividade estruturada. Para outros autores, no entanto, não resta dúvida de que a capacidade de resolução de problemas dos alunos é aprimorada em situações que requisitam a linguagem 
de programação, o que foi explicado pelo desenvolvimento de habilidades como classificação, seriação e conservação (CLEMENTS, 1985, citado por JONASSEN e REEVES, 1996).

Um outro aspecto do debate sobre as aplicaçôes das linguagens de programação na Educação Básica, diz respeito à demanda por aprender uma sintaxe de comandos, para a qual os aplicativos de compilação, que transformam a sequiência de comandos em instruçôes binárias, não admitem erros. Nessas circunstâncias, o domínio da sintaxe da linguagem de programação é um pré-requisito sem o qual o aluno não avança nas atividades de resolução de problemas. Pontuação, espaços, ordem das operações e outros requisitos sintáticos constituem um extenso conjunto de regras, que se não forem cumpridas, inviabilizam o processamento computacional e, portanto, a interação aluno-computador, conforme observado por Jonassen e Reeves (1996, p. 702), ao contrário das regras de sintaxe da linguagem humana, que mesmo não sendo estritamente seguidas, não impedem a interação entre os alunos. É fato que sendo a linguagem estruturadora da comunicação, seja entre pessoas ou entre pessoas e máquinas, ela condiciona o desenvolvimento de funções mentais superiores, a aprendizagem e, portanto, as ações da sala de aula, com ou sem computador. A "suavização" das interfaces computacionais na forma de ambientes de programação orientados por objeto, ou ainda contendo recursos de verificação da compilaçãó guagens de programação. No entanto, a transferência de habilidades de comunicação pessoamáquina desenvolvidas em meio às atividades de programação de computadores para outras situações de resolução de problema não foi verificada em diversas pesquisas (PALUMBO, 1990).

Micromundo é um campo de utilização do computador na escola, diretamente vinculado à evolução do Logo, tendo tido desdobramentos na Educação Matemática e na Educação em Ciências. Sarama e Clements definem micromundo como "um ambiente computacional pequeno e coerente consistindo de ferramentas, estruturas e/ou atividades, que refletem ou incorporam um domínio da Matemática ou da Ciência, e, portanto, promove o aprendizado por meio de exploração, proposição e resolução de problemas" (2002, p. 2). Trata-se de uma definição abrangente, ampliada ainda mais por Papert ao sugerir que os valores da Matemática podem ser levados em conta quando se projetam micromundos primariamente vistos como pertencentes a outros domínios $(2002$, p. 12). Nessa perspectiva, os micromundos seriam projetados para a educação escolar de forma generalizada e para diferentes culturas, o que poderia se viabilizar na medida em que cada aluno tivesse acesso a um computador portátil personalizado, conforme defende Papert (p. 11).

À parte dessa visão centralista sobre o lugar do computador na escola, inspirada pela dinamicidade do meio como forma de superar as restrições epistemológicas impostas por papel e lápis, Papert suprime as condicionantes da linguagem ou das formas de representação na elaboração de significados quando afirma não haver conseqüências importantes do uso de ícones ou texto para movimentar a "máquina de pensamento" (2002, p. 13). Se considerarmos a prioridade conferida para atividades de exploração na construção de significados, consuma-se a visão isenta das condicionantes dos meios de mediação nessa linha de pesquisa, que é, a nosso ver, sua principal falha.

Parece-nos que já existe um movimento para assegurar algum papel para a estrutura das atividades, ou ao menos da interação com o ambiente, conforme relatado por Stenvenson (2002). Ele chama de Ambiente de Manipulação Direta os ambientes computacionais de simulação, como, por exemplo, o aplicativo Interactive Physics ${ }^{5}$, por meio dos quais se torna

\footnotetext{
${ }^{4}$ Estamos nos referindo, aqui aos módulos debug presentes em diversos ambientes de programação.

${ }^{5}$ Roth, Woszczyna e Smith (1996) realizaram um estudo esclarecedor sobre as potencialidades e limitaçôes desse aplicativo, analisando o tempo dedicado à aprendizagem do aplicativo e à interação entre alunos.
} 
explícita a ferramenta matemática que determina o comportamento do modelo computacional. Neste sentido, é evidente que se trata de um processo de modelização matemática, que, segundo o autor, tem a vantagem de exigir uma "carga" menor de aprendizagem de programação que a linguagem Logo. Apesar disso, os ambientes de manipulação direta não demandam tanto o domínio das ferramentas matemáticas e, por essa razão, eles podem subsidiar em maior grau a intuição física e o engajamento dos alunos. Stenvenson interpreta corretamente esse pendor para a ambiência e acerta também quando sugere que se deve olhar as ações dos alunos na presença do ambiente, procurando articular diferentes meios de registro. Porém, é certo que a permanente tensão entre alunos construírem seu próprio conhecimento e suas interaçôes uns com os outros é menos um gerador de categorias, do que o reconhecimento da necessidade de planejar e estruturar as atividades.

Em seu estudo sobre a criação de comunidades para o desenvolvimento de micromundos em contextos multiorganizacionais, Kynigos (2002, p. 208) reconhece a necessidade de estruturar as atividades em um nível correto de generalidade de modo a preservar o interesse de todas as comunidades envolvidas. Já Reed e Jazo (2002), utilizando múltiplas formas de representação, gráfico, animação, simulação e função algébrica, advogam pela necessidade de prover os alunos com um conjunto diversificado de meios para representar situações de deslocamento de objetos. Na linha da mudança conceitual, Tao e Gunstone (1999) verificaram que o uso de um micromundo de força e movimento por alunos da escola secundária, organizados em duplas, sustentou a elaboração de conhecimento compartilhado durante atividades colaborativas. Nesses três estudos, percebe-se a importância de condicionantes socioculturais como a interação, os meios mediacionais e a estrutura das atividades para compreender-se o papel dos micromundos na organização do ensino e na sustentação da aprendizagem. Portanto, mesmo partindo de uma perspectiva de construcionista exploratória de matriz cognitivista, é flagrante a percepção de que, seja na programação ou na simulação de eventos - qualquer que seja a vertente da comunidade de micromundos -, a interação entre pessoas é fator condicionante das formas de ação, juntamente com as ferramentas matemáticas, icônicas ou com outras ferramentas culturais.

A polêmica sobre as contribuições das linguagens de programação para a educação básica está longe de terminar, pela simples razão de não se tratar apenas de questões de pesquisa suscitadas quando da ida do computador para a sala de aula. Elas remontam embates sobre a precedência do desenvolvimento das funções mentais superiores e a aprendizagem. Portanto, a presença do computador na sala de aula, além de se tratar de um movimento recente, mesmo em países desenvolvidos, resgata também questões de pesquisa disputadas por grupos que se apóiam em princípios mais ou menos centrados no indivíduo ou no social, como referência para compreender o desenvolvimento cognitivo e a aprendizagem. Ainda assim, a inspiração para os estudos sobre o papel do computador na sala de aula de ciências não se resume ao inusitado das aplicações dessa tecnologia na escola e às questões de pesquisa desdobradas dos debates sobre psicologia do desenvolvimento. $\mathrm{O}$ fato de o computador reunir os principais meios de representação e de transformar a natureza da comunicação humana justificam a necessidade de se estudar as repercussões do seu uso sobre facetas da teoria do conhecimento e seus desdobramentos na sala de aula, pois nas açóes com o computador tanto o estatuto do fenômeno se nutre da noção de simulação (GIORDAN, 1999) como os atos comunicativos admitem a enunciação das muitas "vozes da aldeia global" (GIORDAN, 1998).

\section{Sistemas tutoriais}

Antes, porém, de tratar de aspectos relacionados à simulação e à comunicação mediada por computador, vale a pena considerar outras experiências do seu uso, que tiveram 
lugar ainda quando a capacidade de processamento limitava as aplicações gráficas ou ainda quando as redes de computadores estavam restritas aos mundos acadêmico e militar. Programar o computador para substituir o professor na sala de aula foi desde o princípio o objeto do desejo de uma parcela dos especialistas em instrução assistida pelo computador $(\mathrm{CAI})^{6}$. Neste sentido, a elaboração de tutoriais de ensino tem sido adotada como solução para essa controvertida finalidade, seguindo inicialmente os princípios da teoria comportamentalista, cuja estratégia, resumidamente, era obter respostas do aluno às perguntas suscitadas pelo aplicativo e avaliá-las mediante o critério de ajustamento ao conteúdo previamente exposto.

Diferentemente de outros materiais de apoio ao ensino, o computador propicia um certo grau de interatividade, na medida em que o feedback fornecido pela máquina pode ser programado em função da resposta do aluno. $\mathrm{Na}$ tradição da instrução assistida por computador, uma das funçōes do feedback é avaliar se a resposta do aluno é correta ou não (WAINWRIGHT, 1989). No caso de ser correta, o aplicativo dá seqüência à apresentação do conteúdo, para então apresentar outro teste que avalia a efetividade da comunicação tutorial-aluno. Se a resposta for incorreta, o aplicativo redireciona o aluno para uma justificativa sobre a resposta correta, para então retornar à seqüência apresentação-teste. Ainda assim, outras pesquisas sugerem diferentes funçôes para o feedback, conforme relata Mory em uma extensa revisão sobre o assunto (MORY, 1996).

Alguma sofisticação no feedback, como oferecer uma justificativa para o correto considerando o diagnóstico e a classificação das respostas incorretas, agrega ao tutorial um certo grau de "inteligência”, na opinião de vários pesquisadores dessa área (SHUTE e PSOTKA, 1996, p. 576-7). Outra contribuição para o aprimoramento dos sistemas tutoriais foi a transposição dos resultados das pesquisas sobre concepções alternativas, modelos mentais e andaimes para o diagnóstico dos erros cometidos pelos alunos e para as próprias estratégias de remediação, o que foi relatado por Shute e Psotka $(1996,573-4)$ em uma revisão sobre o tema. Considerar, por exemplo, as concepções alternativas dos alunos, que têm sido extensamente diagnosticadas, na preparação dos sistemas tutoriais inteligentes é uma das estratégias sugeridas por esses autores, o que pode ser confirmado em estudos recentes sobre o desenvolvimento de ambientes de aprendizagem (SOLOMONIDOU e STRAVIDOU, 2001). Estes estudos indicam um possível desdobramento dos resultados das pesquisas sobre Educação em Ciências e sobre a sala de aula para a área de sistemas tutoriais inteligentes e nos leva a especular sobre a intenção de introduzir as vozes dos alunos, representadas pelas concepções alternativas, na estruturação dos sistemas tutoriais como estratégia para aprimorar o diálogo entre os tutoriais e os alunos.

Talvez pelo fato de pesquisas sobre as formas de interação na sala de aula terem demonstrado a preponderância das tríades IRF, iniciação-resposta-feedback (SINCLAIR e COULTARD, 1975; MEHAN, 1979; CAZDEN, 2001), a metáfora da máquina de ensinar tenha tido forte apelo entre os segmentos alinhados com a perspectiva de transmissão de informação. Em que pese as limitaçôes iniciais para esse tipo de interação, normalmente condicionada a perguntas de múltipla escolha, não se pode desprezar o fato de a fusão de mídias no computador permitir criar narrativas, que até então não conheciam meio de difusão semelhante. Os críticos dos sistemas tutoriais costumam ignorar esse aspecto, preferindo creditar a principal contribuição do computador às oportunidades de descobrimento pelo aluno, como defende Papert quando trata da aprendizagem de uma língua como um processo natural e equipara-a à aprendizagem da linguagem de programação (1985, p. 18), desconsiderando, portanto, o caráter de construção social da linguagem e suas repercussões para o processo de aprendizagem.

${ }^{6}$ Do inglês, CAI é o acrônimo de computer-aided instruction. 
A despeito das críticas sobre os aplicativos tutoriais encerrarem características de treinamento e prática, sua aceitação nas escolas não pode ser desprezada ou mesmo explicada simplesmente com base nas pressōes da indústria de software, ou ainda no desconhecimento sobre as potencialidades do computador. Segundo Crook (1994, p. 13-14), a popularidade da aprendizagem assistida por computador, conforme relatado por Cuban (1986, citado por CROOK, 1994), pode ser devida à pronta reação a uma indesejada demanda imposta pela inovação tecnológica e também pode estar refletindo o comprometimento dos professores com as práticas de ensino vigentes. No entanto, consideramos que para saber quanto ainda se trata de resistência ou desconhecimento e quanto se trata de apego aos modelos de prática já consolidados, é preciso investigar as experiências de utilização do computador e as representações dos professores sobre essa tecnologia, para então avaliarmos como os tutoriais estão sendo usados e como podem vir a ser usados na sala de aula.

\section{Caixas de ferramentas}

Entre os estudiosos da área, prevalece também a idéia de que o desenvolvimento do computador influencia fortemente seu uso na escola, tanto assim que a miniaturização pode ser considerada como um dos fatores que possibilitaram a popularização dessa tecnologia, ao permitir o acesso dos usuários domésticos ao processamento e armazenamento massivo de informação no computador de mesa, o que Breton sugere ser uma verdadeira ruptura, capaz de ter disseminado a "cultura informática" (BRETON, 1991, p. 242-50). Um outro aspecto do desenvolvimento dos computadores que influencia suas aplicações escolares são os efeitos produzidos pelas interfaces gráficas, que vêm sendo aprimoradas desde a criação do ambiente de janelas.

Como exemplos de influência desses ambientes para impulsionar as aplicações educacionais dos computadores, consideremos dois fatores: em primeiro lugar, pelo fato de a comunicação entre usuário e computador ser feita por meio de ícones, a execução dos aplicativos não exige conhecimento de programação por parte do aluno. Tornar a interação alunocomputador mais intuitiva, por meio da iconografia, significa liberá-lo para se concentrar na interação com o próprio aplicativo e, portanto, tratar o aplicativo como uma ferramenta para resolução de problemas, em lugar de levar o aluno a construir a própria ferramenta, como ocorre na programação. $\mathrm{O}$ segundo fator diz respeito à conjugação das representaçóes escritas, imagéticas e sonoras em um único aplicativo, o que diversifica significativamente as aplicações educacionais.

Os chamados aplicativos de escritório, por meio dos quais o usuário cria textos escritos, adiciona imagens e animações, desenha figuras, constrói tabelas e gráficos, são exemplos da diversificação das aplicações educacionais dos computadores, que se tornaram possíveis a partir do desenvolvimento do ambiente de janelas. Ao observar crianças durante atividades de produção de texto, por meio de editores eletrônicos, e de produção de desenhos, por meio de aplicativos de pintura na tela, Crook sugeriu que nessas situações as ferramentas eletrônicas de produção de textos e desenhos podem cultivar nas crianças atitudes de editoração, como revisar suas produções (CROOK, 1992), o que não foi observado por Kumpulainen (1996). Por tratar-se de aplicativos abertos, nos quais a produção de representações é determinada diretamente pelas ações do aluno, entendemos que sendo tais ações mediadas por esses aplicativos, suas propriedades servem de parâmetros para estruturar tanto as ações externas, junto aos aplicativos, quanto as ações internas. Assim, a seleção de trechos de um texto ou desenho, que é executada pelo aluno por meio da ferramenta, passa a interferir na ação de selecionar, a qual o 
aluno executa no plano interno. É sob essa perspectiva que entendemos, assim como Crook, a metáfora da "caixa de ferramentas" como esses aplicativos vêm sendo designados, ou seja, como meios mediacionais capazes de transformar o caráter das ações mediadas. Sugerir que o caráter das ações mediadas é transformado não significa afirmar que ações como revisar textos sejam estimuladas ou mesmo aperfeiçoadas em decorrência de alguma propriedade do editor de texto, mas sim que as estruturas dessas ações são diferentes daquelas que se realizam com papel e lápis.

Em sua revisão de estudos sobre diferentes formas de uso do computador com a finalidade de desenvolver ferramentas cognitivas, Jonassen e Reeves mencionam a inexistência de pesquisas acerca de planilhas, qualificando de especulativos os resultados desses estudos (1996, p. 713). Entendemos, no entanto, que na Educação em Ciências podem ser abertas diversas frentes de pesquisa circunstanciadas no estudo das interaçóes entre alunos e aplicativos para construção planilhas, gráficos ou textos. Investigar, por exemplo, a função da construção de planilhas na identificação de regularidades e variaçôes de uma propriedade de materiais, quando essa construção aparece associada à representação gráfica, pode contribuir para compreendermos como o aluno, ao agir com cada um desses meios mediacionais, organiza sua narrativa para justificar o comportamento da propriedade e os usos dos materiais. É possível também investigar a priorização de um ou outro meio mediacional na resolução de problemas em diferentes situações que envolvam ou não a experimentação e se esta priorização ganha visibilidade na narrativa do aluno, seja na forma de reconstrução da situação experimental ou da própria problematização.

\section{Simulação e animação}

A combinação da característica iconográfica com a convergência dos meios de representação no ambiente de janelas também é particularmente atrativa para a Educação em Ciências, especialmente quando consideramos a transposição do fenômeno do meio natural para o computador. São basicamente três as formas de transposição do fenômeno: a reprodução em tela do fenômeno filmado, a animação obtida pela seqüência de ilustraçóes e a simulação por meio da combinação de um conjunto de variáveis de modo a reproduzir as leis que interpretam o fenômeno. Neste trabalho, trataremos da simulação e da animação.

Um conjunto de investigações realizadas por um grupo de psicólogos tratando do uso de animações em situações de ensino é bastante ilustrativo da ausência de uma preocupação estética ou mesmo estrutural com a animação. Há já uma extensa literatura sobre a combinação de meios de veiculação das representações pictóricas, escritas, sonoras, gráfica etc., e seus efeitos sobre a aprendizagem, como as pesquisas produzidas pelos grupos liderados por Rieber (1990) e Mayer, que, no entanto, não discutem a animação como um meio capaz de veicular diferentes gêneros discursivos.

Tomemos como exemplo os estudos de Mayer e colaboradores, que são fundamentados pela Teoria da Codificação Dual (PAIVIO, 1986), que por sua vez se orientam por estudos envolvendo imagem e texto em sistemas multimodais (MAYER, 1989). Do ponto de vista dessa teoria, três tipos de conexões entre palavras e imagens são construídos em situações de ensino envolvendo multimídia: a) conexão representacional entre a informação verbal nova e a representação verbal do aluno; b) conexão representacional entre a informação imagética nova e a representação visual do aluno; c) conexão referencial entre os elementos correspondentes das representaçôes imagética e verbal do aluno. Trata-se, portanto, de uma teoria de matriz cognitivista-conexionista que adota, entre outros princípios, o paralelismo entre as macroestruturas de representação verbal e imagética e o princípio da contigüidade (MAYER e ANDERSON, 1992). 
Baseados nos princípios da Teoria de Codificação Dual, Mayer e colaboradores organizaram experimentos de caráter avaliativo de desempenho, nos quais as seqüências de animação e narração (oral ou escrita) envolvendo dispositivos mecânicos eram combinadas. A partir dessas combinações, algumas questôes de pesquisa foram examinadas, como por exemplo, colocar à prova o princípio da contigüidade (MAYER e ANDERSON, 1992), confrontar habilidade espacial com seqüências de animações e narrações (MAYER e SIMS, 1994), comparar a influência da representação oral e da representação escrita sobre animações (MAYER e col., 1996), verificar a ocorrência do efeito desdobramento de atenção em animações multimídia envolvendo a concomitância de atenção visual imagética e escrita (MAYER e MORENO, 1998).

Entre as conclusōes, recomenda-se usar canais sonoros para expressão verbal simultaneamente à veiculação da animação, pois nesse arranjo os recursos de memória-detrabalho são menos exigidos quando comparados à representação verbal escrita (MAYER e MORENO, 1998). Os autores consideraram que seu estudo foi o primeiro a verificar que os estudantes aprendem melhor quando uma narração oral é apresentada durante uma animação do que quando textos são apresentados ao mesmo tempo em que a animação. A concomitância de representações é decorrente do princípio da contigüidade e está sempre presente nos estudos do grupo.

Por ser de fundo conexionista, a justificativa para a contigüidade temporal entre narração e animação está no fato de o contato entre palavras e imagens encorajar os alunos a construir conexôes entre as representaçōes verbal e visual da informação de entrada, o que por seu lado sustenta a transferência para a solução de problemas (MAYER e ANDERSON, 1992, p. 450). É certo, portanto, que a informação está associada à palavra e à imagem, tendo pouca ou nenhuma consideração a locução que por si só já acrescenta elementos da temporalidade. De fato, a abordagem do tempo nesses estudos limita-se à linearidade das seqüências narração-animação e não reconhece o entremeado intertextual que já está presente na narrativa oral, escrita ou imagética.

Mesmo que se ignorem alguns condicionantes do contexto dos experimentos, particularmente a experiência prévia dos alunos com dispositivos mecânicos e as características do material de apoio, é razoável considerar que há muitos outros aspectos importantes a serem investigados, além da verificação da determinação das imagens e da fala sobre a construção de significado. É exatamente a natureza dessa determinação e de suas articulações com as atividades de ensino que podem subsidiar tanto a compreensão das formas como os alunos agem em situações de proposição e resolução de problemas, como o planejamento das funcionalidades do ambiente, pelo qual os meios mediacionais icônico, gráfico e animado serão veiculados. Se a contigüidade é um elemento constitutivo de qualquer narrativa audiovisual e, ao mesmo tempo, as conexões entre representaçôes visuais e verbais são parte das hipóteses da Teoria da Codificação Dual, então disso parece decorrer que a estrutura temporal da narrativa deve ser coerentemente disposta no tempo para que as conexôes entre as representaçóes se efetivem. Definir objetivamente os meios para anunciar a voz do narrador e as vozes dos alunos ao longo da atividade, a organização espacial desses meios e suas funcionalidades, são atitudes práticas que podem contribuir decisivamente para o desenvolvimento de gêneros discursivos específicos que sustentem uma gama diversificada de atividades envolvendo elementos de animação.

Por outro lado, nos aplicativos de simulação, transpóe-se o fenômeno para o plano simulado mediante a programação do computador, de modo a reproduzir as leis físicas que regem o fenômeno e de modo, também a representar simultaneamente o fenômeno na tela do computador. Esta é a mudança de fundo no estatuto do fenômeno, do ponto de vista da teoria do 
conhecimento. Em vista da justaposição do controle das variáveis embutidas nas leis físicas à representação visual do próprio fenômeno, sugerimos que, durante a elaboração de narrativas explicativas, o aluno poderá se referir tanto aos ditames teóricos, quanto aos eventos empíricos circunscritos ao fenômeno, o que poderá contribuir para a apropriação dos dispositivos de pensamento característicos da comunidade científica. Assim, a conjugação teórica e empírica do fenômeno simulado pelo computador, diferentemente da animação ou da reprodução audiovisual, torna-se uma referência ímpar nas situaçôes em que o aluno trabalha na resolução de problemas diante do computador. Nossa hipótese prevê que na medida em que o aluno se apropria desses dispositivos sociotécnicos, a estrutura de seus dispositivos de pensamento é influenciada pela conjugação teoria-empiria, repercutindo tanto nos seus discursos, como nas formas de agir. Esta seria a principal contribuição dos estudos sobre os fenômenos simulados para a Educação em Ciências, do ponto de vista da teoria do conhecimento. Nas circunstâncias em que a atenção do aluno esteja mobilizada por uma aplicação simuladora do fenômeno, o controle sobre as variáveis pode ser exercido com o intuito de observar regularidades, fazer previsões, ou ainda a própria representação do fenômeno simulado pode servir de suporte para o aluno elaborar narrativas ou explicações acerca do fenômeno no meio natural. Conforme sugerimos anteriormente, o controle sobre temperatura, pressão e volume de gases pode ser mais eficiente para fins de elaboração de modelos, quando cada uma dessas variáveis do sistema experimental é convertida em um análogo do fenômeno simulado (GIORDAN, 1999), e pode ser, portanto, modificada, o que permite ao aluno fazer previsões sobre os efeitos das variações.

Solomonidou e Stavridou (2001) relataram o desenho e o desenvolvimento de um ambiente de aprendizagem que contém simulações e visualizações de experimentos sobre equilíbrio químico, simulaçōes de reações químicas representadas no nível atômico-molecular, que na verdade podem ser consideradas como animações, representações simbólicas das reações químicas, gráficos dinâmicos e uma seqüência de problemas por meio dos quais a lei de constante de equilíbrio é derivada. Uma das características desse estudo diz respeito à influência da pesquisa das concepções dos alunos sobre equilíbrio químico no desenho e desenvolvimento da arquitetura do ambiente de aprendizagem. Apesar de as autoras considerarem essa como a principal característica do ambiente para promover a mudança nas concepçôes dos alunos, por meio de situações de conflito cognitivo, parece-nos que a combinação entre as formas estática e dinâmica de representação do fenômeno - macroscópico, atômico-molecular, simbólico e matemático - em uma única tela aliada à possibilidade de intervenção dos alunos nos parâmetros e variáveis do sistema, provêem os alunos com os meios mediacionais necessários para executar ações, sendo estes os traços distintos que repercutem tanto na resolução de problemas, quanto na elaboração de narrativas explicativas. Portanto, o uso orientado de meios mediacionais para a resolução de problemas, os quais situam os alunos no contexto da fenomenologia do equilíbrio químico ${ }^{7}$ é aquilo que determina suas ações, as quais repercutem na elaboração de significados, sem que necessariamente ocorra conflito cognitivo. Para dirimir o conflito dessas hipóteses, sugerimos investigar se, nas situações de interação com o ambiente de aprendizagem, os dispositivos de pensamento característicos das concepções alternativas inventariadas em inúmeros estudos - estão presentes nas narrativas dos alunos e então analisar se suas estruturas e funções se preservam quando os meios mediacionais do ambiente de aprendizagem estão à disposição dos alunos.

\footnotetext{
${ }^{7}$ Nesta aproximação, a resolução de problemas embute os propósitos das ações mediadas, bem como a narrativa deflagadora da situação, e portanto do contexto, por meio do qual se orienta o diálogo do aluno para outras situaçóes do cotidiano da sala de aula e de outros contextos.
} 
De modo geral, a simulação tem sido pouco empregada como meio para transpor o fenômeno para o computador. Na maior parte dos casos, animações são embutidas em ambientes de aprendizagem, as quais estão integradas a outras aplicaçôes (GREDLER, 1996, p. 523). Nem mesmo para a representação do experimento tem sido observada a programação de aplicativos no sentido de fazê-los reproduzir alguma lei, mesmo que seja empírica. No caso da representação do nível atômico-molecular, é mais comum observar a influência de leis da mecânica molecular na programação dos aplicativos; no entanto, a influência da dinâmica molecular é menos comum. Nesses casos, os aplicativos se restringem à visualização dos objetos moleculares.

Chamamos de objetos moleculares as representações dessas partículas submicroscópicas, cujo meio de veiculação pode variar desde o papel, passando pelos conjuntos plásticos, isopor e madeira, chegando à tela do computador ou à projeção holográfica. Varia-se o meio e também as formas de representação, nesse caso com o objetivo de destacar uma ou outra propriedade da molécula. Portanto, o objeto molecular é uma entidade iconográfica que serve tanto para propósitos de indexação e referência, como para mimetizar determinada propriedade molecular, tendo esta a característica de ser simulada por meio de um sistema de equaçóes quando o objeto é veiculado pelo computador. Exemplos simples de objetos moleculares podem ser vistos em livros didáticos e em artigos científicos, servindo de referência para designar uma molécula, como o benzeno, abaixo.
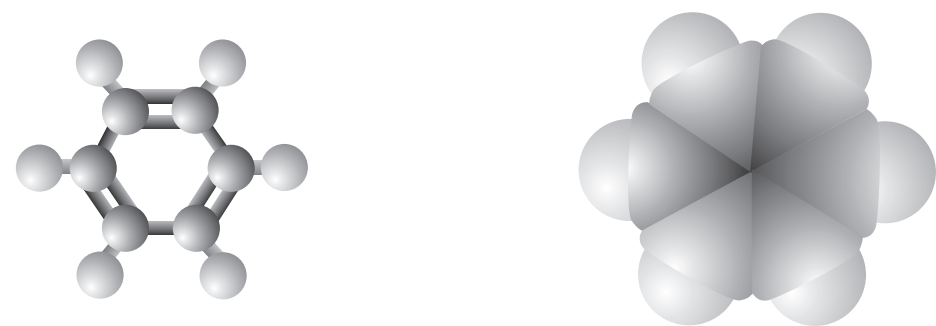

Figura 2 - Representações da molécula de benzeno.

Caso se deseje destacar alguma propriedade molecular, como, por exemplo, as distâncias de ligação, outras formas de representação são mais adequadas, sobretudo se o computador puder ser utilizado para tal. Nesse meio, a representação do objeto molecular é mediada por um conjunto de equações que obedecem a determinadas leis da mecânica clássica ou da mecânica quântica, o que confere ao usuário a capacidade de manipular o objeto sob diversas formas de representação, controlando facilmente algumas variáveis do sistema.

Uma decorrência importante da manipulação de diversas formas de representação é a possibilidade de conferir um efeito vinculante entre a variável, de natureza teórica, e a forma de representação da propriedade, de natureza imagética. A visualização de objetos moleculares mediada pelo computador parece, portanto, promover a vinculação entre a simulação de uma propriedade da molécula e sua representação em um mesmo meio. Esta é uma situação de alto valor didático capaz de mobilizar as açōes dos alunos na manipulação do objeto, na elaboração discursiva e também na elaboração de significado. Em um artigo recente, descrevemos um ambiente computacional que permite construir representações animadas e simuladas do objeto molecular, no qual as funcionalidades descritas acima estão implementadas (GIORDAN e GÓIS, 2005). A concepção sociocultural subjacente ao desenvolvimento do ambiente "construtor", além de propiciar um contraponto à perspectiva construcionista, defendida por Ribeiro e Greca (2003) em revisão sobre simulações e modelização na Educação em Química, também organizar um cenário de pesquisa para dar resposta às questôes que se seguem. 
Existe também uma extensa literatura sobre visualização molecular. Lazlo (1995) discute amplamente questôes de natureza lingüística em seu livro A palavra das coisas ou a linguagem da quimica, sendo uma referência importante no debate sobre linguagem química. Yamalidou (2001) sugere a utilização de objetos moleculares tridimensionais em situações de ensino, após uma profícua discussão sobre o discurso dos molecularistas britânicos do século XIX. A estética das representações moleculares também é discutida por Spector (2003), que se concentra na análise de tabelas de afinidades e da simbologia introduzida por Dalton sugerindo que ele tenha sido o precursor de uma transformação epistêmica e estética de formas de representação na química dos séculos XIX e XX.

Visualizaçōes estáticas foram estudadas por Gabel e Bunce (1991), e por Williamson e Abraham (1995) indicando um aumento do entendimento dos alunos sobre os níveis macroscópico, submicroscópcio e simbólico. Nesses estudos, a visualização molecular sustentou a elaboração de modelos mais compatíveis com os fenômenos submicroscópicos. Entretanto, os modelos estáticos são deficientes para descrever a natureza dinâmica de alguns processos estudados pelos alunos, como verificado nos estudos sobre equilíbrio químico de Solomonidou e Stavridou (2001), e Kozma e col. (1996). Outras questões sobre referencialidade e indexação dos objetos moleculares foram estudadas seguindo uma linha de processamento de informação, na qual os autores observaram que muitos alunos não foram capazes de "traduzir" fórmula, distribuição eletrônica e modelos "bola-vareta" (KEIG \& RUBBA, 1993).

Um dos trabalhos importantes a ser considerado no debate sobre visualização molecular e seus desdobramentos na Educação em Química foi relatado por Wu, Krajcik e Soloway (2001). Adotando a Teoria da Codificação Dual, o trabalho segue o mesmo referencial teórico em que se apoiaram os estudos sobre animações de Mayer e colaboradores. No entanto, os estudos abordam fenomenologias diferentes, o que nos permite avaliar a sustentação dessa teoria quando questões sobre a estrutura da matéria estão em pauta. Desde o princípio, Wu e colaboradores adaptaram os três tipos de conexão dos níveis representacionais, substituindo o nível verbal pelo conceitual, para estudar como alunos desenvolvem seu entendimento sobre representações químicas por meio da utilização de uma ferramenta de visualização.

A metodologia de pesquisa baseada na aplicação de pré e pós-testes forneceu um conjunto de informações sobre o desempenho dos alunos na resolução de problemas envolvendo conhecimento de representação química (fórmula e estrutura), distribuição eletrônica, nomenclatura, polaridade de ligações, temperatura de ebulição e solubilidade. Desses resultados, observou-se um aumento significativo no desempenho após os alunos terem participado de atividades com a ferramenta de visualização. Diversos outros incrementos no entendimento de conceitos de química orgânica, na habilidade de transformar formas de representação e no entendimento de propriedades e estruturas foram constatados nas entrevistas.

Não há dúvida sobre a funcionalidade da ferramenta de visualização e também sobre a engenhosidade da organização dessa pesquisa. No entanto, a estrutura das atividades nas quais os alunos estiveram envolvidos indica ter havido descontinuidade e compartimentação ${ }^{8}$ das ações, além da ausência de questôes problematizadoras. À ferramenta de visualização não foram agregados outros meios mediacionais, por meio dos quais se estruturasse um ambiente, onde aspectos visuais, verbais e gestuais pudessem organizar coerentemente as narrativas. Alienada essa perspectiva, parece-nos improvável avaliar como os três níveis de conexões são ativados e se é plausível observar a transferência de representações, pelo menos da forma como

${ }^{8}$ Por exemplo, organizar uma atividade para os alunos visualizarem representaçôes $2 D$ e 3D, outra para introduzir a nomenclatura Iupac. 
os autores argumentam, quando afirmam que a tradução entre representações químicas pode envolver não apenas a recuperação de conhecimento conceitual, mas também a criação de imagens mentais.

Certamente, imagens mentais tomam parte nas açôes internas na medida em que os alunos agem com imagens externas cuja função também é a referencialidade. Copolo e Hounshell (1995) observaram que os alunos têm diferentes preferências por diferentes tipos de modelos ou sistemas simbólicos, assim como o estudo de Harrison \& Tregust (1996) mostrou que os alunos têm uma forte tendência a selecionar a representação de espaço preenchido em determinadas situações. No entanto, para saber mais a respeito dessas preferências, é preciso considerar como os alunos agem com os objetos moleculares de acordo com todos os condicionantes de uma ação determinadamente mediada. Neste sentido, parece-nos que para responder a perguntas sobre como os alunos interagem com diferentes formas de representação, é preciso ir além da metodologia de pré e pós-testes e se concentrar mais sobre a estrutura das atividades de ensino e sobre o próprio cenário experimental.

No que se refere às atividades de ensino, o efeito realístico da visualização molecular deve ser aproveitado para sustentar a elaboração de modelos ou narrativas explicativas, mesmo considerando que os objetos moleculares visualizados possam vir a ser elevados ao status de reprodução da "realidade" do nível atômico-molecular. Isso porque não nos parece que o apelo visual da representação molecular seja o fator determinante da formação de visões realísticas de ciências. Nisso, as formas de deferência ao objeto representado são mais influentes ${ }^{9}$, e por essa razão deve-se considerar o diálogo como ação prioritária nas atividades de ensino, mais ainda quando se exige confrontar realismo e consensualismo na sala de aula de ciências.

\section{Comunicação mediada por computador}

É evidente que a interação do aluno com os aplicativos de simulação ou com sistemas tutoriais não esgota as formas de uso do computador na Educação em Ciências. Uma forma de se contrapor ao realismo da visualização molecular é fomentar o diálogo dos alunos entre si, de modo a realçar a busca do consenso como um dos propósitos das atividades que se realizam diante do computador. Esse diálogo pode ocorrer em interações na presença do computador, sobre o que discorreremos adiante e também por meio do computador. Tanto assim, que a comunicação mediada por computador é uma das formas de aplicação mais investigadas no contexto da educação escolar, principalmente após a disseminação do uso da internet, sobre a qual passaremos a fazer um breve relato histórico.

A comunicação mediada por computador se concretiza por meio de redes de computadores, uma idéia que surgiu em meio a muitas iniciativas desencadeadas pelo governo dos Estados Unidos quando do lançamento do primeiro satélite no espaço, na segunda metade da década de 1950. Por iniciativa do Departamento de Defesa, iniciaram-se estudos com vistas a desenvolver um sistema de troca de informação entre os computadores, que já eram reconhecidos como principais recursos para processar e armazenar informações. Prevaleceu, na época, uma proposta de troca de informação por meio de pequenos pacotes, em contraposição à idéia de trocas de grandes volumes de informação. $\mathrm{O}$ modelo de comutação de pacotes, no qual os computadores ficam permanentemente conectados, culminou com o desenvolvimento de um protocolo de troca de pacotes e, finalmente, com sua padronização. A publicação do protocolo TCP/IP

\footnotetext{
${ }^{9}$ Referir-se aos entes representados como os próprios entes, figura de linguagem conhecida como metonimia, pode se configurar em um obstáculo verbal mais prejudicial à construção do conhecimento do que a metáfora do objeto molecular, na medida em que pela metonímia não se evidencia o caráter de modelização da molécula.
} 
é considerada o marco de fundação da internet, o que ocorreu em 1980, onze anos após a primeira experiência de conexão de computadores a longa distância.

A internet foi rapidamente adotada no meio universitário internacional, mas sua popularização só teve início após a gigante Microsoft ter admitido que a comunicação em rede seria a principal aplicação dos computadores, isso já em meados da década de 1990, quando foi lançado seu navegador. Antes disso, a troca de arquivos e mensagens era mediada por interfaces que exigiam do usuário o domínio de uma sintaxe de comandos relativamente complexa. Em 1993, foi lançada a primeira versão do aplicativo que permitia a leitura de documentos no formato de hipertexto e que aproveitava a propriedade de integrar escrita, imagem e som, além de viabilizar a conexão entre computadores por meio de vínculos acionados por um simples pressionar de botão. Sem dúvida, a popularização da internet é devida à suavização das interfaces de comunicação usuário-computador, simplificada pela "linguagem estruturada de hipertexto". No entanto, não se pode desconsiderar o esforço gigantesco de empresas de computadores, softwares e telecomunicações, e de governos em vender a idéia da Sociedade da Informação, ainda que no Brasil as escolas públicas tenham permanecido à margem dos projetos oficiais. ${ }^{10}$

As aplicações da internet na escola básica são, hoje em dia, reconhecidamente variadas. Alinhando nossos interesses de pesquisa com a necessidade de focar a discussão sobre temáticas específicas, optamos aqui por abordar as experiências e estudos sobre as interaçôes entre alunos por meio do computador, mesmo sabendo do potencial educacional do imenso banco de dados da teia hipertextual. Muitos dos estudos sobre comunicação mediada por computador (CMC) na escola têm sido realizados por pesquisadores da área de linguagem, talvez pelo fato de a internet ter permitido uma interação rápida e de baixo custo entre falantes de línguas diferentes. No início da década de 1990, já era possível observar os efeitos da CMC sobre as atitudes de alunos do Ensino Médio em programas de intercâmbio entre escolas bilíngues do México e dos Estados Unidos (MEAGHER e CASTAÑOS, 1996). A análise semântica de respostas a questionários, sugeriu que a CMC facilitou a percepção dos valores culturais pelos estudantes, o que foi corroborado posteriormente pela análise do conteúdo das mensagens de correio eletrônico.

Se por um lado a estrutura não hierarquizada e o potencial para encorajar a aprendizagem colaborativa são duas características da internet que justificam o desenvolvimento de atividades de ensino mediadas por listas de discussão (CRONJÉ, 2001), por outro a diversidade de modos comunicacionais e as dificuldades para planejar atividades de ensino podem inibir a integração da internet nas práticas de sala de aula, especialmente se os professores não recebem formação específica (DAWES, 1999). Também a heterogeneidade dos gêneros discursivos das mensagens de correio eletrônico pode ser afetada por numerosos fatores específicos da situação e da estrutura social, os quais determinam o evento comunicacional em andamento (YATES, 1996, p. 46). Mesmo sendo veiculados por textos escritos, os estudos que procuram caracterizar as locuções de correio eletrônico como mais assemelhadas à escrita ou à fala têm afirmado que a complexidade das formas enunciativas é um indício de que estamos diante de um inusitado meio de comunicação (BARON, 1998; GIORDAN, 2000).

Do ponto de vista da estrutura dos diálogos realizados por meio do correio eletrônico, tem-se observado que os alunos fazem uso de perguntas como principal estratégia de interação (CRONJÉ, 2001; MEIJ e BOERSMA, 2002) durante atividades estruturadas de ensino na sala de aula. Esta atitude também foi observada em atividades extra-sala de aula, nas quais os alunos procuravam espontaneamente um serviço de tutoria, cuja interação tutor-aluno se

${ }^{10}$ No final de 1999, foi lançado o Programa Brasileiro para a Sociedade da Informação, sobre o qual fizemos uma análise da perspectiva educacional (GIORDAN, 2000). 
baseava na troca de mensagens por correio eletrônico (GIORDAN e MELLO, 2001). A análise dessas perguntas demonstrou que os alunos as elaboram com vistas a resolver problemas suscitados na sala de aula.

Também com o propósito de vincular as atividades que se desenvolvem no interior da sala de aula de ciências daquelas realizadas por meio do correio eletrônico, tem-se observado um crescente interesse em desenvolver ambientes, na internet, que subsidiem a interação dialogada entre alunos, principalmente com vistas a valorizar a argumentação (BELL e LIN, 2000; RAVESCROFT, 2000). Esses trabalhos partem do princípio de que os alunos podem aprender ciências a partir de discussóes assíncronas estruturadas, como sugeriram os resultados de um estudo em que se comparou a influência de comentários e de textos narrativos na consecução de um debate histórico sobre a luz e seu espectro de cores (HOADLEY e LINN, 2000). Neste sentido, o planejamento das atividades realizadas por meio de correio eletrônico parece desempenhar uma função determinante sobre a efetividade das ações dos alunos, cuja estrutura está visível no movimento discursivo dos diálogos mediados pelo correio eletrônico. Portanto, a análise dos diálogos se constitui em um valioso procedimento de investigação para compreender não apenas como os significados estão sendo elaborados, mas também como proceder ao planejamento de atividades mediadas pelo correio eletrônico.

Os resultados desses estudos sugerem ainda a possibilidade de ocorrer o prolongamento das interaçôes síncronas da sala de aula para as interações assíncronas do correio eletrônico, o que pode ampliar os meios e as formas como as locuções são enunciadas. Parece-nos que o valor desse prolongamento de interaçôes para a Educação em Ciências está em orientar o planejamento das atividades de ensino de modo a absorver o correio eletrônico na organização dessas atividades e simultaneamente incentivar o diálogo das vozes enunciadas por locuções faladas e escritas, e assim subsidiar a vinculação das ações. Partindo desse princípio, seria possível investigar as situaçôes de sala de aula com os enfoques do ensino ou da aprendizagem e confrontar com os resultados de pesquisa sobre a ansiedade dos professores em relação às tecnologias da comunicação e informação (RUSSELL e BRADLEY, 1997), ou sobre as concepções dos professores a respeito do uso do computador na sala de aula (DRENOIYANNI e SELWOOD, 1998), ou sobre as atitudes dos alunos em relação aos usos educacionais do computador (SELWYN, 1999), os quais desconsideram a análise das ações na sala de aula como uma conduta investigativa necessária para compreender o ensino e a aprendizagem.

Diversas outras experiências de comunicação pela internet entre escolas de diferentes contextos culturais têm sido relatadas (GARNER e GILLINGHAN, 1996), a partir das quais pode-se depreender um vasto campo de investigação desde perspectivas multiculturais, lingüísticas, etnográficas, comunitárias, e sob diversos outros enfoques dentro da Educação em Ciências, como as chamadas parcerias alunos-cientistas (COHEN, 1997). Além da modalidade assíncrona, a comunicação mediada por computador tem sido explorada em situações de salas de bate-papo da internet (internet relay chat), onde os alunos se comunicam em tempo real (INGRAN, HATHORN e EVANS, 2000). Neste sentido, os programas de pesquisa que têm como referência o fato de as interações dialogadas da sala de aula serem situadas em um contexto sociocultural singular e de essas interações determinarem as ações externas e internas dos alunos, dispõem de uma nova modalidade de comunicação para ser investigada. 


\section{A dinâmica das interaçóes da sala de aula na presença do computador}

Esses programas de pesquisa têm uma longa tradição no estudo das interações dialogadas da sala de aula. A natureza desses diálogos vem sendo estudada de forma sistemática a partir do seu registro e de variadas técnicas de análise, de modo que já há uma vasta literatura de revisōes sobre o tema (EDWARDS e WESTGATE, 1994; HICKS, 1995; WELLS, 1999; CAZDEN, 2001). Esses estudos são unânimes em constatar que a estrutura IRF foi um dos primeiros padróes discursivos registrados em salas de aula inglesas (SINCLAIR e COULTHARD, 1975) e norte-americanas (MEHAN, 1979), e que também tem sido observada em salas de aula brasileiras (MACHADO, 1999; CAPECHI e CARVALHO, 2000; MORTIMER, 2000) e mexicanas (CANDELA, 1999). Por meio de Iniciações, o professor normalmente se dirige aos alunos na forma de perguntas que são Respondidas e recebem uma apreciação do professor, normalmente avaliativa, na forma de Feedback. Analisando episódios de aulas de ciências no Ensino Secundário, Lemke (1990) observou o mesmo padrão discursivo ao qual chamou de Diálogo Triádico, asseverando se tratar de uma estrutura básica de comunicação dessas salas de aula, por meio da qual o professor controla o fluxo do diálogo e o próprio padrão temático. Da mesma forma, ao observarem que os professores usavam o feedback para revozear os alunos com o intuito de confirmar ou reformular seus enunciados, Edwards e Mercer (1987) também se referiram ao IRF como um meio de manter o controle sobre as estruturas discursiva e temática dos episódios de ensino.

No entanto, o controle assimétrico exercido pelo professor sobre o fluxo do diálogo não é a única função exercida pela tríade. Conforme foi observado por Wells (1993), o terceiro movimento pode ser usado para dar seqüência ao diálogo no sentido de estender a resposta do aluno ou fazer ligações com outras passagens do episódio de ensino ou de episódios anteriores. Por sua vez, Candela (1999) observou que os alunos são capazes de reverter a tríade em situações de negociação de significado, nas quais eles resistem à versão do professor por não estarem em acordo com ela. Essa inversão das tríades também foi observada em uma situação de tutoria pela internet, na qual a aluna exerceu controle parcial sobre o fluxo do diálogo e sobre o padrão temático, iniciando, ela mesma, a interação com perguntas, o que foi considerado uma forma de debate por correio eletrônico (GIORDAN, 2004).

Para as situações em que apenas os alunos são os interlocutores diretos, a diversidade das modalidades discursivas pode aumentar consideravelmente, conforme indica a característica multifuncional das locuções observada por Barnes e Todd (1995) em estudos sobre atividades colaborativas entre alunos do Ensino Fundamental. Sob forte influência bakhtiniana na segunda edição de seu livro, os autores sugeriram que o significado é indeterminado e está distribuído entre as trocas enunciativas em lugar de ser inerente a qualquer uma delas (1995, p. 141).

De fato, estudos recentes sobre o papel da audiência, ou seja, do endereçado no processo enunciativo (HERRENKOHL e GUERRA, 1998), situações de trabalho colaborativo com e sem a intervenção do professor (HOGAN, NASTASI e PRESSLEY, 2000), interação escritaoralidade em pequenos e grandes grupos de discussão (MASON, 1998), as funçôes de perguntas de alunos e professores em discussões guiadas (ZEE e col., 2001), os papéis desempenhados pelos alunos em atividades práticas mediadas pelo computador (KELLY e CRAWFORD, 1996; KELLY, CRAWFORD e GREEN, 2001), e sobre o desenvolvimento de ferramentas de análise e planejamento de ensino com base nos conceitos de narrativa, interação e dialogia (MORTIMER e SCOTT, 2002), indicam a ocorrência de diversas modalidades discursivas nas salas de aula de ciências. 
No mesmo sentido dos estudos que tratam o diálogo como elemento estrutural das atividades da sala de aula, investigações sobre como os alunos do Ensino Fundamental conversam em atividades realizadas diante do computador também têm contribuído para a compreensão da natureza das interações de ensino e aprendizagem (WEGERIF e SCRIMSHAW, 1997). Da análise dessas interaçôes diante do computador, foram sugeridas três formas de diálogos, chamados de cumulativo, disputativo e exploratório (FISCHER, 1997), cujas semelhanças com os tipos de diálogos observados na ausência do computador (MERCER, 1997) indicam que a estrutura de determinadas atividades colaborativas em pequenos grupos podem ser intercambiadas entre situações com e sem a presença do computador. Outra contribuição importante desse grupo de pesquisa foi a constatação de uma seqüência de locuções, entre os movimentos de iniciação e resposta na tríade IRF, que foram chamadas de Discussão (de onde propuseram o quarteto IDRF), dada a natureza exploratória dos diálogos (WEGERIF e MERCER, 1996). Nesses casos, o aplicativo computacional foi responsável pelos movimentos de iniciação e seqüência, e não de avaliação, como se observa freqüentemente em diálogos triádicos entre professor e alunos.

Em um número especial sobre deliberação com computadores, um conjunto de investigações trouxe novos indícios de que o computador pode e de fato inicia, modela distintamente e apóia diálogos educativos (LITTLETON e WEGERIF, 2003, p. 790). Em sua crítica às investigações, Wertsch (2003) destaca a existência de vínculos genéticos entre os planos intermental e intramental também em situações nas quais o computador é o meio mediacional estruturante das ações. Esta sinalização nos permite levantar a hipótese de que a correlação entre as formas de uso do computador e de apropriação dos gêneros discursivos é a chave para compreendermos como e por que estas novas formas de mediação estão vinculadas às formas de pensamento. Atividades estruturadas na comunicação mediada por computador que estimulam o aluno a perguntar e descrever com detalhes suas dúvidas, indicaram, por vezes, a possibilidade de o aluno ocupar uma posição de controle sobre o fluxo do diálogo, algo como uma subversão de tríades IRF (GIORDAN, 2003) e, por outras, a possibilidade de domínio do silogismo lógico e do gênero hipotético-dedutivo (GIORDAN, 2004).

\section{Perspectivas}

Nesta breve revisão de estudos sobre as seis principais formas de uso do computador em aulas de ciências, defendemos a necessidade de se investigar como alunos e professor interagem diante do computador em situações de ensino. Este nos parece ser o cenário prioritário de pesquisa quando se pretende avaliar as possibilidades e limitaçôes de uso de um meio mediacional que condiciona fortemente as ações de ensino e também os processos de aprendizagem e desenvolvimento de funçôes mentais superiores. Estes cenários são ainda mais prioritários se considerarmos as alterações nas noçôes de audiência e de fenômeno, resultantes das formas de interação que se vislumbram com essa tecnologia.

Eis que os computadores chegaram às escolas e os professores continuam a exercer sua profissão, sem que tenham sido substituídos por máquinas, como ocorreu em muitos outros setores do mundo do trabalho. Parece-nos que há mais demanda por esse profissional do que em épocas remotas, o que certamente se explica pelo aumento da população, e não por algum "milagre" tecnológico. Porém, a pressão pela demanda desses profissionais não é apenas quantitativa; exige-se cada vez mais de suas competências em lidar com o mundo governado por redes, sejam elas de informação, de produção, ou mesmo de poder. A sala de aula é mais que um nó de uma rede, pois desde sempre as ações que ali se desenvolvem têm sido influenciadas por 
intensos diálogos de cada um de seus agentes entre si e com suas comunidades. Ainda que esses diálogos venham sendo subestimados, a sala de aula é sempre uma rede dialógica de interações. Se o computador será usado para fortalecer essa rede é uma questão que diz respeito a um complexo sistema de relaçóes culturais, políticas, econômicas e fundamentalmente educacionais.

Antes de nos atrevermos a censurar ou recomendar formas de uso, na sala de aula, de uma tecnologia decididamente incrustada na sociedade, devemos ser moderados e reconhecer que é necessário investigar o que ali se passa, com a única certeza de que buscamos respostas para perguntas que possam nos lançar para além da atmosfera conservadora que caracteriza os momentos de ruptura paradigmática. Sob esse aspecto, a comunidade de Educação em Ciências não pode se omitir, e deve, portanto, ocupar seu papel de interlocutora preferencial da sociedade, pois é pelo diálogo que os mitos serão despidos.

\section{Referências}

BAKHTIN, M. M. The dialogic imagination: four essays. Austin: University of Texas Press, 1981.

BARNES, D.; TODD, F. Communication and learning revisited: making meaning through talk. Portsmouth: Boynton/Cook, 1995.

BARON, N. S. Letters by phone or speech by other means: the linguistics of e-mail. Language and Communication, Oxford, v. 18, p. 133-170, 1998.

BELL, P.; LIN, M. Scientific arguments as learning artifacts: designing for learning from the web with KIE. International Journal of Science Education, London, v. 22, p. 797-817, 2000.

BRASIL. Ministério da Educação. Secretaria de Educação a Distância. Programa nacional de informática na educação. Brasília, DF, 1999. Disponível em: <http://www.proinfo.gov.br>. Acesso em: 19.nov.2003.

BRETON, P. História da informática. São Paulo: Editora Unesp, 1991.

BURKE, K. A grammar of motives. Berkeley: University of California Press, 1969.

The philosophy of literary form. 3 ed. Berkeley: University of California Press, 1973.

CANDELA, A. Students' power in classroom discourse. Linguistics and Education, v. 10, n. 2, p. 139-163, 1999.

CAPECCHI, M. C. V. M.; CARVALHO, A. M. P. Argumentação em uma aula de conhecimento físico com crianças na faixa de oito a dez anos. Investigaçōes em Ensino de Ciências, Porto Alegre, v. 5, n. 3, dez. 2000. Disponível em: <http://www.if.ufrgs.br/public/ensino/revista.htm>. Acesso em: 23.mar.2006

CAZDEN, C. B. The language of teaching and learning. Portsmouth: Heinemann, 2001.

CLEMENTS, D. H. Research in Logo in education: is the turtle slow but steady or not even in the race? Computers in the Schools, v. 2, n. 2-3, p. 55-71, 1985. 
COHEN, K. C. Internet links for science education: student-scientist partnerships. New York: Plenum, 1997.

CONFERÊNCIA DE PESQUISA SOCIOCULTURAL, 3, 2000, Campinas. Anais... Campinas: [s.n.], 2000.

COPOLO, C. F.; HOUNSHELL, P. B. Using three-dimensional models to teach molecular structures in high school chemistry. Journal of Science Education and Technology, v. 4, n. 4, p. 295-305, 1995.

CRONJÉ, J. C. Metaphors and models in internet-based learning. Computers and Education, New York, v. 37, p. 241-256, 2001.

CROOK, C. Young children's skill in using a mouse to control a graphical computer interface.

Computers and Education, New York, v. 19, p. 199-207, 1992.

Computers and the collaborative experience of learning. London: Routledge, 1994.

CUBAN, L. Teachers and machines. New York: Teachers College Press, 1986.

DAWES, L. First connections: teachers and the National Grid for Learning. Computers and Education, New York, v. 33, p. 235-252, 1999.

DRENOYIANNI, H.; SELWOOD, I. D. Conceptions or misconceptions? Primary teachers' perceptions and uses of computers in the education. Education and Information Technologies, New York, v. 3, n. 2, p. 87-99, 1998.

EDWARDS, A. D.; WESTGATE, D. P. G. Investigating classroom talk. London: Falmer, 1994.

EDWARDS, D.; MERCER, N. Common knowledge: the development of understanding in the classroom. London: Routledge, 1987.

ENCONTRO INTERNACIONAL LINGUAGEM, CULTURA E COGNIÇÃO, 2, 2003, Belo Horizonte. Anais... Belo Horizonte: [s.n.], 2003.

FISCHER, E. Educationally important types of children's talk. In: WEGERIF, R.; SCRIMSHAW, P. (Ed.). Computers and talk in primary classroom. London: Multilingual Matters, 1997.

GABEL, D. L.; BUNCE, D. M. Improving chemistry achievement through emphasis on the particulate nature of matter. In: ANNUAL NARST CONFERENCE, 64, 1991, Lake Geneva. Proceedings... Lake Geneva: [s.n.], 1991.

GARNER, R.; GILLINGHAM, M. G. Internet communication in six classroom: converstations across time, space, and culture. Mahwah: Lawrence Erlbaum, 1996.

GIORDAN, M. Correio e bate-papo: a oralidade e a escrita ontem e hoje. Química Nova na Escola, São Paulo, n. 8, p. 17-19, 1998.

. O papel da experimentação no ensino de ciências. Quimica Nova na Escola, São Paulo, n. 10, p. 43-49, 1999. 
O programa brasileiro para a sociedade da informação e suas bases educacionais. Jornal da USP, São Paulo, n. 506, p.8, 2000.

The role of IRF exchanges in the discursive dynamics of e-mail tutored interactions.

International Journal of Educational Research, Oxford, v. 39, p. 817-827, 2003.

Tutoring through the internet: how students and teachers interact to construct meaning. International Journal of Science Education, London, v. 26, n. 15, p. 1875-1894, 2004.

A Internet vai à escola: domínio e apropriação de ferramentas culturais. Educação e Pesquisa, São Paulo, v. 31, n. 1, p. 57-78, 2005.

GIORDAN, M.; GÓIS, J. Telemática educacional e ensino de química: considerações em torno do desenvolvimento de um construtor de objetos moleculares. Revista Latinoamericana de Tecnología Educativa, Badajoz, v. 3, n. 2, p. 41-59, 2005.

GIORDAN, M.; MELLO, I. C. Tutoring through telematics in teaching and learning chemistry. In: EUROPEAN CONFERENCE ON RESEARCH IN CHEMICAL EDUCATION, 6., 2001, Aveiro. [Trabalho apresentado]. Aveiro: [s.n.], 2001.

GREDLER, M. E. Educational games and simulations: a technoloy in search of a (research) paradigm. In: JONASSEN, D. H. (Ed.). Handbook of research for educational communications and technology. New York: Macmillan, 1996. p. 521-540.

HARRISON, A. G.; TREAGUST, D.F. Secondary students' mental models of atoms and molecules: Implications for teaching chemistry. Science Education, New York, v. 80, n. 5, p. 509-534, 1996.

HERRENKOHL, L. R.; GUERRA, M. R. Participant structures, scientific discourse, and student engagement in fourth grade. Cognition and Instruction, Mahwah, v. 16, n. 4, p. 431-473, 1998.

HICKS, D. Discourse, Learning, and Teaching. Review in Research Education, New York, v. 21, p. 49-95, 1995.

HOADLEY, C. M.; LINN, M. C. Teaching science through on-line, peer discussions: SpeakEasy in the Knowledge Integration Environment. International Journal of Science Education, London, v. 22, n. 8, p. 839-857, 2000.

HOGAN, K.; NASTASI, B. K.; PRESSLEY, M. Discourse patterns and collaborative scientific reasoning in peer and teacher-guided discussions. Cognition and Instruction, Mahwah, v. 17, n. 4, p. 379-432, 2000.

HUGHES, M. Children's computation. In: GRIEVE, R.; HUGHES, M. (Ed.). Understanding children. Oxford: Basil Blackwell, 1990.

INGRAM, A. L.; HATHORN, L. G.; EVANS, A. Beyond chat on the internet. Computers \& Education, New York, v. 35, p. 21-35, 2000. 
JONASSEN, D. H.; REEVES, T. C. Learning with technology: using computers as cognitive tools. In: JONASSEN, D. H. (Ed.). Handbook of research for educational communications and technology. New York: Macmillan, 1996. p. 693-719.

KEIG, P. F.; RUBBA, P. A. Translation of representations of the structure of matter and its relationship to reasoning, gender, spatial reasoning, and specific prior knowledge. Journal of Research in Science Teaching, New York, v. 30, n. 8, p. 883-903, 1993.

KELLY, G.; CRAWFORD, T.; GREEN, J. Common task and uncommon knowledge: dissenting voices in the discursive construction of physics across small laboratory groups. Linguistics and Education, New York, v. 12, n. 2, p. 135-174, 2001.

KELLY, G. J.; CRAWFORD, T. Students' interaction with computer representations: analysis of discourse in laboratory groups. Journal of Research in Science Teaching, New York, v. 33, n. 7, p. 693-707, 1996.

KOZMA, R. B. et al. The use of multiple, linked representations to facilitate science understanding. In: VOSNIADOU, R. G. S.; DECORTE, E.; MANDEL, H. (Ed.). International perspective on the psychological foundations of technology-based learning environments. Hillsdale: Erlbaum, 1996. p. 41-60.

KUMPULAINEN, K. The nature of peer interaction in the social context created by the use of word processors. Learning and Instruction, Oxford, v. 6, n. 3, p. 243-261, 1996.

KYNIGOS, C. Generating cultures form mathematical microworlds development in a multi-organizational context. Journal of Educational Computing Research, Farmingdale, v. 27, p.182-211, 2002.

LANG, M. Teacher development of computer use in education in Germany. Education and Information Technologies, New York, v. 5, n. 1, p. 39-48, 2000.

LASZLO, P. A palavra das coisas ou a linguagem da química. Lisboa: Gradiva, 1995.

LEMKE, J. L. Talking science: language, learning, and values. Norwood: Ablex, 1990.

LITTLETON, K.; WEGERIF, R. Special issue on deliberation with computers: exploring the distinctive contribution of new technologies to collaborative thinking and learning. International Journal of Educational Research, Oxford, v. 39, p. 787-791, 2003.

MACHADO, A. H. Aula de quimica. Ijui: Unijui, 1999.

MASON, L. Sharing cognition to construct scientific knowledge in school context: the role of oral and written discourse. Instructional Science, Amsterdam, v. 26, p. 359-389, 1998.

MAYER, R. E. et al. When less is more: meaningful learning from visual and verbal summaries of science textbook lesson. Journal of Educational Psychology, Arlington, v. 88, n. 1, p. 64-73, 1996.

MAYER, R. E. Systematic thinking fostered by illustrations in scientific text. Journal of Educational Psychology, Arlington, v. 81, p. 240-246, 1989. 
MAYER, R. E.; ANDERSON, R. B. The instructive animation: helping students build connections between words and pictures in multimedia learning. Journal of Educational Psychology, Arlington, v. 84, n. 4, p. 444-452, 1992.

MAYER, R. E.; MORENO, R. A split-attention effect in multimedia learning: evidence for dual processing systems in working memory. Journal of Educational Psychology, Arlington, v. 90, n. 2, p. 312320, 1998.

MAYER, R. E.; SIMS, V. K. For whom is a picture worth a thousand words? Extensions of a dualcoding theory of multimedia learning. Journal of Educational Psychology, Arlington, v. 86, n. 3, p. 389-401, 1994.

MEAGHER, M. E.; CASTAÑOS, F. Perceptions of American Culture: the impact of an electronically-mediated cultural exchange program on Mexican high school students. In: HERRING, S. C. (Ed.). Computer-mediated communication: linguistic, social and cross-cultural perspectives. Philadelphia: John Pub Co, 1996. p. 187-202.

MEHAN, H. Learning lessons. Cambridge: Harvard Press, 1979.

MERCER, N. La construcción guiada del conocimiento. Barcelona: Paidós, 1997.

MORTIMER, E. F. Linguagem e formação de conceitos no ensino de ciências. Belo Horizonte: Ed. UFMG, 2000.

MORTIMER, E. F.; SCOTT, P. Atividade discursiva nas salas de aula de ciências: uma ferramenta sociocultural para analisar e planejar o ensino. Investigaçôes em Ensino de Ciências, Porto Alegre, v. 7, n. 2, 2002. Disponível em: <http://www.if.ufrgs.br/public/ensino/revista.htm>. Acesso em: 23.mar.2006

MORY, E. H. Feedback Research. In: JONASSEN, D. H. (Ed.). Handbook of research for educational communications and technology. New York: Macmillan, 1996. p. 919-956.

PAIVO, A. Mental representations: a dual-coding approach. New York: Oxford Uni Press, 1986.

PALUMBO, D. B. Program language/problem solving research: a review of relevant issues. Review of Educational Research, Washington, v. 60, p. 65-89, 1990.

PAPERT, S. Logo: computadores e educação. São Paulo: Brasiliense, 1985.

The turtle's long slow trip: marco-educological perspectives on micro worlds. Journal of Educational Computing Research, Farmingdale, v. 27, p. 7-27, 2002.

PELGRUM, W. J. Obstacles to the integration of ICT in education: results from a worldwide educational assessment. Computers \& Education, New York, v. 37, p. 163-178, 2001.

RAVENSCROFT, A. Designing argumentation for conceptual development. Computers \& Education, New York, v. 34, p. 241-255, 2000. 
REED, S. K.; JAZO, L. Using multiple representation to improve conceptions of average speed. Journal of Educational Computing Research, Farmingdale, v. 27, p.147-166, 2002.

RIBEIRO, A. A.; GRECA, I. M. Simulaçōes computacionais e ferramentas de modelização em Educação Química: uma revisão de literatura publicada. Química Nova, São Paulo, v. 26, n. 4, p. 542-549, 2003.

RIEBER, L. P. Animation in computer-based instruction. Educational Technology Research and Development, Washington, v. 38, p. 77-86, 1990.

ROTH, Wolff-Michael; WOSZCZYNA, C.; SMITH, G. Affordances and constraints of computers in science education. Journal of Research in Science Teaching, New York, v. 33, n. 9, p. 995-1017, 1996.

RUSSEL, G.; BRADLEY, G. Teachers' computer anxiety: implications for professional development. Education and Information Technologies, New York, v. 2, p. 17-30, 1997.

SARAMA, J.; CLEMENTS, D. H. Design of micro worlds in mathematics and science education. J. Educational Computing Research, Farmingdale, v. 27, p. 1-5, 2002.

SELWYN, N. Students' attitudes towards computers in sixteen to nineteen education. Education and Information Technologies, New York, v. 4, n. 2, p. 129-141, 1999.

SHUTE, V. J.; PSOTKA, J. Intelligent tutoring systems: past, present and future. In: JONASSEN, D. H. (Ed.). Handbook of research for educational communications and technology. New York: Macmillan, 1996. p. 570-600.

SINCLAIR, J. McH.; COULTHARD, R. M. Towards an analysis of discourse: the English used by teachers and pupils. London: Oxford Univ. Press, 1975.

SOLOMONIDOU, C.; STRAVIDOU, H. Design and development of a computer learning environment on the basis of students' initial conceptions and learning difficulties about chemical equilibrium. Education and Information Technologies, New York, v. 6, n. 1, p. 5-27, 2001.

SOMEKH, B. New technology and Learning: policy and practice in the UK, 1980-2010. Education and Information Technologies, New York, v. 5, n. 1, p. 19-37, 2000.

SPECTOR, T. J. The aesthetics of molecular representation: from the empirical to the constitutive. Foundations of Chemistry, Dordrecht, v. 5, p. 215-236, 2003.

STENVENSON, I. Micro worlds and direct manipulation environments: the case of Newtonian mechanics. Journal of Educational Computing Research, Farmingdale, v. 27, p. 167-183, 2002.

TAO, P-K.; GUNSTONE, R. F. Conceptual change in science through collaborative learning at the computer. International Journal of Science Education, London, v. 21, n. 1, p. 39-57, 1999.

VAN DER MEIJ, H.; BOERSMA, K. E-mail use in elementary school: an analysis of exchange patterns and content. British Journal of Educational Technology, London, v. 33, n. 2, p. 189-200, 2002. 
VAN ZEE, E. H.et al. Student and Teacher Questioning during Conversations about Science. Journal of Research in Science Teaching, New York, v. 38, n. 2, p. 159-190, 2001.

WAINWRIGHT, C. L. The effectiveness of a computer-assisted instruction package in high school chemistry. Journal of Research in Science Teaching, New York, v. 26, n. 4, p. 275-290, 1989.

WEGERIF, R. Thinking skills, technology and learning: a review of the literature for NESTAFuturelab. Milton Keynes: [s.n.], 2003.

WEGERIF, R.; MERCER, N. Computers and reasoning through talk in the classroom. Language and Education, Clevedon, v. 10, n. 1, p. 47-64, 1996.

WEGERIF, R.; SCRIMSHAW, P. (Ed.). Computers and talk in primary classroom. London: Multilingual Matters, 1997.

WELLS, G. Reevaluating the IRF sequence: a proposal for the articulation of theories of activity and discourse for the analysis of teaching and learning in the classroom. Linguistics and Education, New York, v. 5, p. 1-37, 1993.

Dialogic Inquiry. Cambridge: Cambridge Uni Press, 1999.

WERTCH, J. V. (Ed.). The concept of activity in Soviet psychology. New York: M. E. Sharpe, 1981. Vygostky and the social formation of the mind. Cambridge: Harvard Uni Press, 1985. . Voices of the mind. Cambridge: Harvard Uni Press, 1991. Mind as action. New York: Oxford Uni Press, 1998. Voices of collective remembering. New York: Cambridge Uni Press, 2002.

. Commentary on: deliberation with computers: exploring the distinctive contribution of new technologies to collaborative thinking and learning. International Journal of Educational Research, Oxford, v. 39, p. 899-904, 2003.

WERTSCH, J. V.; DEL RÍO, P.; ALVAREZ, A. (Ed.). Sociocultural studies of the mind. Cambridge: Cambridge Uni. Press, 1995.

WILLIAMSON, V. M.; ABRAHAM, M. R. The effects of computer animation on the particulate mental models of college chemistry students. Journal of Research in Science Teaching, New York, v. 32, p. 521-534, 1995.

WU, H.; KRAJCIK, J. S.; SOLOWAY, J. Promoting understanding of chemical representations: students' use of a visualization tool in the classroom. Journal of Research in Science Teaching, New York, v. 38, n. 7, p. 821-842, 2001. 
YAMALIDOU, M. Molecular representations: building tentative links between the history of science and the study of cognition. Science \& Education, Dordrecht, v. 10, p. 423-451, 2001.

YATES, S. J. Oral and written linguistic aspects of computer conferencing. In: HERRING, S. (Ed.). Computer mediated communication: linguistic, social and cross-cultural perspectives. Philadelphia: John Benjamins, 1996. p. 29-46.

ZINCHENKO, V. P. Vygotsky's ideas about units for the analysis of mind. In: WERTSCH, J. V. (Ed.). Culture, communication and cognition. New York, Cambridge Uni. Press, 1985. p. 94.

Cultural-historical psychology and the psychological theory of activity: retrospect and prospect. In: WERTSCH, J. V.; DEL RÍO, P.; ALAVREZ, A. (Ed.). Sociocultural studies of the mind. Cambridge: Cambridge Uni. Press, 1995. p.37-55.

Artigo recebido em abril de 2004 e selecionado para publicação em outubro de 2005. 